\title{
Animal model of diabetic keratopathy
}

\author{
Pitra Ariesta Shinta Dewi ${ }^{1 *}$, Ratna Sitompul ${ }^{2}$, Jeanne Pawitan ${ }^{3}$, Aroem Naroeni $^{4}$ \\ ${ }^{1}$ Doctoral Programme of Biomedical Sciences, Faculty of Medicine, University of Indonesia, Jakarta \\ ${ }^{2}$ Department of Ophthalmology, Faculty of Medicine, University of Indonesia, Jakarta \\ ${ }^{3}$ Department of Histology, Faculty of Medicine, University of Indonesia, Jakarta \\ ${ }^{4}$ Virology and Cancer Pathobiology Research Center, University of Indonesia, Jakarta
}

\begin{abstract}
Diabetic keratopathy is one of the most common ocular complications in diabetes mellitus. Protocol for diabetes induction in rat model also has been established in many centers. Nonetheless, method in developing diabetic keratopathy rat model has not been well covered. Streptozotocin (STZ)-induced diabetes is widely being used as animal diabetic model. The purpose of this study is to obtain an animal model of diabetic keratopathy that can be used to study the morphology, metabolism, and function of cornea in cases where human samples can be difficult to obtain.A single dose STZ (50 mg/kg) was injected intraperitoneally to control and intervention group. Plasma glucose level concentrations were tested in day 3 post injections. Obtained animal model of diabetic keratopathy, with significant difference of blood glucose level between intervention and control group $(\mathrm{P}<0.00)$. Sensibility of cornea was decreased by week $14^{\text {th }}$ in intervention group. Epithelial defect were more prominent in diabetic group. Despite the differences between human and animal characteristic of diabetic keratopathy, the use of animal models has contributed to better understanding of this disease and to examine more effective treatment.
\end{abstract}

Keywords:

diabetic keratopathy, animal model, streptozotocin

\section{- INTRODUCION}

The increasing number of diabetes case in Indonesia is accompanied by increasing complication on the eyes, which leads to vision loss (Wild et al. 2004). Of which, diabetic keratopathy is one of the most common ocular complication in diabetes. Diabetic keratopathy is a disease of the cornea characterized by impaired morphology, metabolism, and function of cornea. Dry eye syndrome and impaired wound healing in diabetic patients also leads to diabetic keratopathy (Yin et al. 2011).

Interaction of glucose and reactive oxygen species in diabetic patients leads to increasing extracellular osmotic stress. This oxidative stress affects mitochondria permeability, activate apoptosis of caspase cells, and induce apoptosis of neuron and Schwann cells. Neuronal apoptosis leads to irreversible nerve damage (Veira-Potter et al. 2016).

Streptozotocin (STZ)-induced diabetes is widely being used as animal diabetic model. Its mechanism in selective destruction of pancreatic B cell is effectively creating insulin deficiency, hypeprglycemia, as well as polydipsia and polyuria state (King 2012). Two protocols used to produce STZ-induced diabetic rat including multiple administrations of low-dose STZ and administration using a single, high dose STZ (Ljubimov 2017).

Protocol for induction of diabetes rat model also has been carried out in many centers. Nonetheless, studies and protocol in developing diabetic keratopathy rat model has not been well covered. The aim of this paper is to share our experience in developing rat model of diabetic keratopathy.

\section{- MATERIALS AND METHODS}

Animal care: Male Sprague-Dawley rats, 3-4 months of age, weighing 250-350 gram were used for the studies. They were housed in $30 \times 40 \times 20 \mathrm{~cm}$ cage with ambient temperature of $25-30^{\circ} \mathrm{C}$, relative humidity of $80-90 \%$, and stable light.

Injection of STZ: Before injection, animals were tested for plasma glucose concentration. They were divided randomly into intervention and control group. A single dose STZ (50 $\mathrm{mg} / \mathrm{kg}$ ) diluted with fresh citric acid solution $(0.01 \mathrm{M} \mathrm{pH}$ 4.5) was injected intraperitoneally. Control group were injected with citric acid buffer. After injection, animals had free access to food. On day 3 post-STZ injection, tail-vein blood sample were drawn. Animals are considered suitable for study when blood glucose level of STZ-injected rat is $\geq 250 \mathrm{mg} / \mathrm{dl}$. If in 3 days glucose level has not reached 250 $\mathrm{mg} / \mathrm{dl}$, rats were given second dose of STZ. Insulin was given daily to prevent adverse effect of severe hyperglycemia.

Received: 12-07-2019 | Revised: 15-08-2019 | Accepted: 21-08-2019

(C) 2019 CC-BY-SA. This is an Open Access article that is distributed under the terms of Creative Commons Attribution ShareAlike 4.0 International License (https://creativecommons.org/licenses/by-sa/4.0/). 
Examination of diabetic keratopathy rat models: On $10^{\text {th }}$ day post-STZ injection, animals were examined using slit lamp bio microscope to assess cornea integrity, irregularity, and epithelial defect. Before examination a single drop of fluorescein eye drop were administered. Sensibility of cornea was assessed using Cochet-Bonnet aesthesiometer.

\section{- RESULTS AND DISCUSSION}

During first week post-STZ induction, average of blood glucose level in diabetic group was $322 \pm 26 \mathrm{mg} / \mathrm{dl}$, compared to normal group $91 \pm 1 \mathrm{mg} / \mathrm{dl}$ (Figure 1). Normal group revealed stable concentration of blood sugar of 89-96 $\mathrm{mg} / \mathrm{dL}$, meanwhile in intervention group using STZinduction, blood sugar level were $266-365 \mathrm{mg} / \mathrm{dL}(\mathrm{P}<0.00)$.

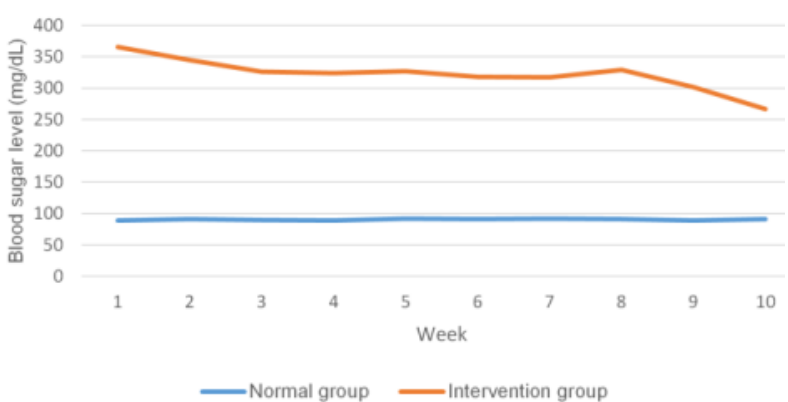

Figure 1 Comparison of blood glucose value between normal and diabetic group.

Clinical examination on keratopathy eyes were conducted on $10^{\text {th }}$ and $14^{\text {th }}$ week post-STZ injection (Figure 2). In diabetic group, there was a significant decrease in cornea sensibility from $55.25 \pm 1.7 \mathrm{~mm}$ in week $10^{\text {th }}$ into $42.75 \pm 1.92$ $\mathrm{mm}$ in ${\text { week } 14^{\text {th }}}(\mathrm{P}=0.012)$. Meanwhile in control group, sensibility of cornea was unremarkable from $59.33 \pm 1.21$ $\mathrm{mm}$ in $10^{\text {th }}$ week into $59.17 \pm 1.21 \mathrm{~mm}$ in $14^{\text {th }}$ week.

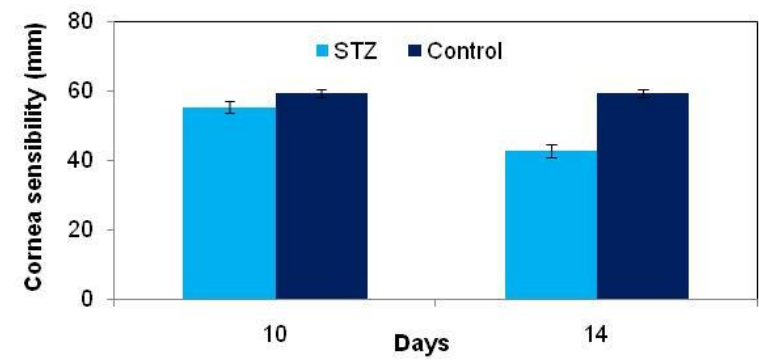

Figure 2 Comparison of cornea sensibility value between normal (Control) and diabetic (STZ) group.

Cornea epithelial defect was examined using fluorescein and slit lamp. Corneal lesion scoring were used to classify degree of lesion, diabetic group showed all subjects suffered from dendritic ulceration in week $14^{\text {th }}$, while in control group 4 subjects had normal epithelial and 2 subjects had punctate ulceration. Cornea lesion was found getting worse in week $14^{\text {th }}$ compared to week $10^{\text {th }}$ in diabetic model.

The significant difference of blood sugar level between intervention and control groups shows the success of diabetes induction by streptozotocin in rats. Our diabetic rats blood glucose level was ranging from $266-365 \mathrm{mg} / \mathrm{dL}$, whereas control rats was $89-96 \mathrm{mg} / \mathrm{dL}(\mathrm{P}<0.00)$. Significant difference between STZ-treatment and control group were the major determinant of diabetes induction success (Furman 2015).

Our study revealed a significant decrease of corneal sensitivity from week $10^{\text {th }}$ compared with week $14^{\text {th }}$, suggesting potential damage of sensory neurons with constant hyperglycemia. Other study revealed decrease of corneal sensitivity in $8^{\text {th }}$ week (Yin et al. 2011, Bikbova et al. 2016). Reduced innervation was prominent in diabetic rats with the reduction of long nerve fibers was documented (Cousen et al. 2007). Reduced innervation also contributing to lacrimal gland function, thus reducing tear protection and contributing to dry eye (Cousen et al. 2007).

Integration of cell junction have vital role in the formation and maintenance of epithelial barrier of epithelia, punctate keratitis is observed in some diabetic patients (Yin et al. 2011). Our study found more severe corneal lesion in diabetic group, including punctate and dendritic keratitis.

\section{- CONCLUSION}

Diabetic keratopathy can lead to morbidity and eventually vision loss. Therefore, model of diabetic keratopathy have been developed in animals to analyze the disease. Despite the differences between human and animal characteristic of diabetic keratopathy, the use of animal models has contributed to better understanding of this disease and to examine more effective treatment.

\section{- AUTHOR INFORMATION}

Corresponding Author

*PASD: pitraariesta@yahoo.com

Doctoral Programme Biomedical Sciences, Faculty of Medicine, Universitas Indonesia, Jakarta

\section{- REFERENCES}

Bikbova G, Oshitari T, Baba T, Yamamoto S. 2016. Neuronal changes in the diabetic cornea: perspectives for neuroprotection. BioMed Research International. 2016:1-8.

Cousen P, Cackett P, Bennett H, Swa K, Dhillon B. 2007. Tear production and corneal sensitivity in diabetes. Journal of Diabetes and its Complications. 21(6):371-373.

Furman BL. 2015.Streptozotocin-induced diabetic models in mice and rats. Current Protocols in Pharmacology. 70(1):5-47.

King AJ. 2012. The use of animal models in diabetes research. British Journal of Pharmacology. 166(3):877-894.

Ljubimov AV. 2017. Diabetic complications in the cornea. Vision Research. 139:138-152.

Vieira-Potter VJ, Karamichos D, Lee DJ. 2016. Ocular complications of diabetes and therapeutic approaches. BioMed Research International. 2016: 1-14.

Wild S, Roglic G, Green A, Sicree R, King H. 2004. Global prevalence of diabetes: estimates for the year 2000 and projections for 2030. Diabetes Care. 27(5):1047-53.

Yin J, Huang J, Chen C, Gao N, Wang F, Fu-Shin XY. 2011. Corneal complications in streptozocin-induced type I diabetic rats. Investigative Ophthalmology \& Visual Science. 52(9):6589-6596. 